\title{
Evolution of External Genitalia: Insights from Reptilian Development
}

\author{
Marissa L. Gredler ${ }^{a}$ Christine E. Larkins $^{b}$ Francisca Leal $^{a} \quad$ A. Kelsey Lewis ${ }^{a}$ \\ Ana M. Herrera $^{b}$ Claire L. Perriton $^{d}$ Thomas J. Sanger $^{\mathrm{b}}$ Martin J. Cohn ${ }^{\text {a-d }}$ \\ Departments of a Biology and ${ }^{b}$ Molecular Genetics and Microbiology, and ${ }^{\mathrm{C} H o w a r d}$ Hughes Medical Institute, UF \\ Genetics Institute, University of Florida, Gainesville, Fla., USA; ${ }^{\mathrm{d}}$ School of Animal and Microbial Sciences, University \\ of Reading, Reading, UK
}

\section{Key Words}

Amniote $\cdot$ Cloaca $\cdot$ Development $\cdot$ External genitalia .

Genital swellings · Hemiclitores · Hemipenes · Phallus .

Sulcus spermaticus · Urethra

\begin{abstract}
External genitalia are found in each of the major clades of amniotes. The phallus is an intromittent organ that functions to deliver sperm into the female reproductive tract for internal fertilization. The cellular and molecular genetic mechanisms of external genital development have begun to be elucidated from studies of the mouse genital tubercle, an embryonic appendage adjacent to the cloaca that is the precursor of the penis and clitoris. Progress in this area has improved our understanding of genitourinary malformations, which are among the most common birth defects in humans, and created new opportunities for comparative studies of other taxa. External genitalia evolve rapidly, which has led to a striking diversity of anatomical forms. Within the past year, studies of external genital development in non-mammalian amniotes, including birds, lizards, snakes, alligators, and turtles, have begun to shed light on the molecular and morphogenetic mechanisms underlying the diversification of phallus morphology. Here, we review recent progress in
\end{abstract}

the comparative developmental biology of external genitalia and discuss the implications of this work for understanding external genital evolution. We address the question of the deep homology (shared common ancestry) of genital structures and of developmental mechanisms, and identify new areas of investigation that can be pursued by taking a comparative approach to studying development of the external genitalia. We propose an evolutionary interpretation of hypospadias, a congenital malformation of the urethra, and discuss how investigations of non-mammalian species can provide novel perspectives on human pathologies.

(c) 2014 S. Karger AG, Basel

Intromittent organs facilitate transfer of sperm for efficient internal fertilization and are found in each of the major vertebrate clades [Leonard and Cordoba-Aguilar, 2010]. Not all intromittent organs are true external genital organs; for example, some fishes use modified fin structures to direct sperm into the female, and the basal frog Ascaphis trueii uses its 'tail' for intromission [Van Dijk, 1959]. Although co-option of organs such as fins for cop-

M.L.G., C.E.L., and F.L. contributed equally to this work.

\begin{tabular}{ll}
\hline KARGER & $\begin{array}{l}\text { @ 2014 S. Karger AG, Basel } \\
\text { 1661-5425/14/0085-0311\$39.50/0 Open carcess }\end{array}$ \\
E-Mail karger@karger.com & $\begin{array}{l}\text { This is an Open Access article licensed under the terms of the } \\
\text { Creative Commons Attribution-NonCommercial 3.0 Un- } \\
\text { ported license (CC BY-NC) (www.karger.com/OA-license), } \\
\text { applicable to the online version of the article only. Distribu- } \\
\text { tion permitted for non-commercial purposes only. }\end{array}$
\end{tabular}

Martin J. Cohn

Department of Molecular Genetics and Microbiology and Department of Biology University of Florida, PO Box 103610

Gainesville, FL 32610 (USA)

E-Mail mjcohn@ufl.edu 


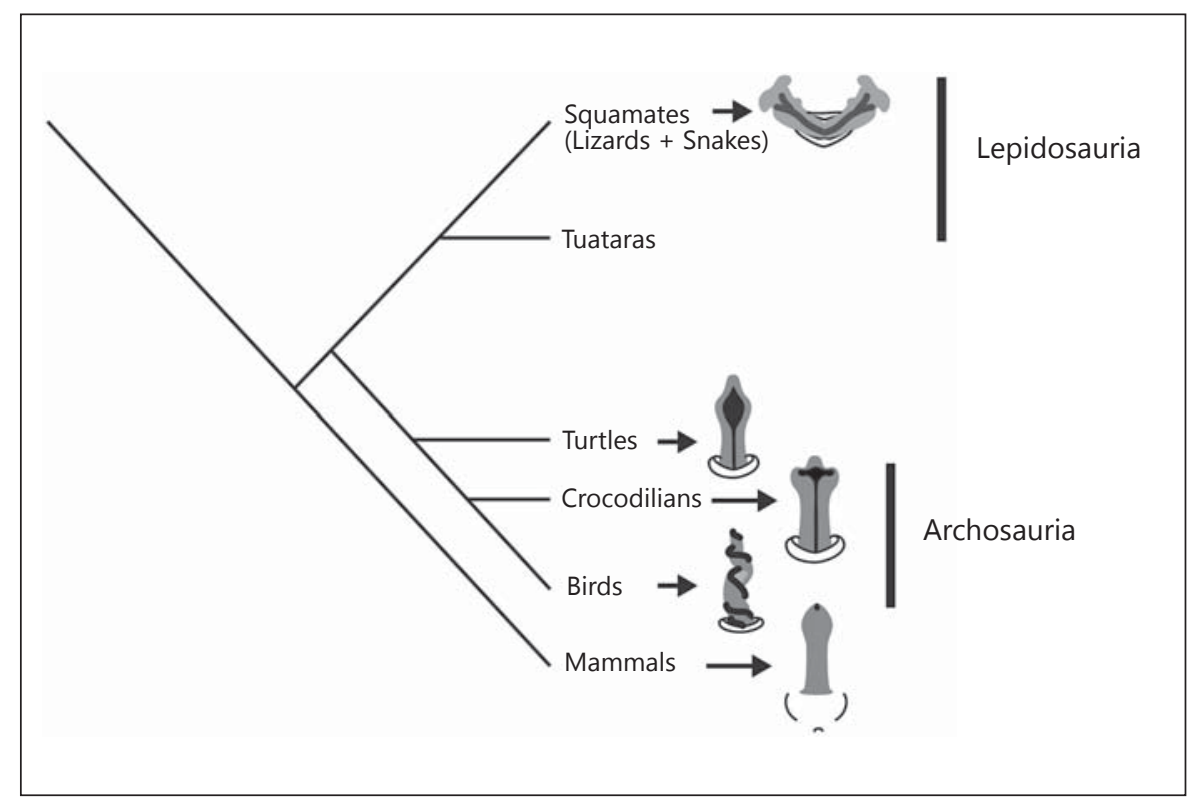

Fig. 1. The diversity of adult genital morphologies among amniote crown groups. Aminote phylogenetic relationships based on the consensus of molecular phylogenomic analyses [Crawford et al., 2012; Wang et al., 2013]. Most amniotes have a single median phallus anterior to the cloaca, with the exception of tuataras, which are reported to lack intromittent organs, and squamates, which possess paired phalluses (hemipenes) lateral to the cloaca. Non-mammalian amniotes have an open sulcus spermaticus (shaded) that is used to transfer sperm to the female reproductive tract during cop-

ulatory function has played an important role in the evolution of internal fertilization, de novo development of a phallus as an external genital organ occurs only in amniotes (mammals + reptiles, including birds) and in the enigmatic amphibian lineage of caecilians [Wake, 1972].

Phallus morphology is one of the most rapidly evolving characteristics among animals, often obtaining speciesspecific size, shape, or ornamentation [Arnqvist, 1998]. This diversity in external genital form has gained the attention of developmental and evolutionary biologists searching for deeper mechanistic understandings of this variation [Simmons and Jones, 2007; Eberhard, 2010; Brennan and Prum, 2012; Herrera et al., 2013]. Both the morphogenesis and the molecular mechanisms of external genital development are only beginning to be understood, based largely on studies of the laboratory mouse [reviewed in Cohn, 2011; Ipulan et al., this issue]. Despite the remarkable morphological diversity that occurs in the external genitalia of squamates (lizards, snakes, and amphisbaenians), turtles, and archosaurs (crocodilians and birds), little is known about development of the phallus ulation. Instead of this sulcus, mammals have an enclosed, tubular urethra that carries both sperm and urine. Note that the penis depicted in birds represents only that of paleognaths and anseriforms; in other birds the penis is reduced or absent. Historically, it has been unclear whether the ancestral condition for amniotes is a single midline phallus, a paired phallus, or whether the last common ancestor lacked external genitalia all together. Tree reproduced from Leal and Cohn [2014].

outside of rodents. Here, we review both classical literature and several recent advances in our understanding of external genital development, with special attention given to reptilian species. We hope that this review will shed new light on the question of the deep homology (shared common ancestry) of these structures, highlight how studies of non-mammalian species can offer a novel perspective to human pathologies, and identify new areas of investigation that can be pursued by taking a comparative approach to studying development of the external genitalia.

\section{Diversity of Amniote External Genitalia}

There are significant differences in both the gross anatomy and the microanatomy of amniote external genitalia. Mammals, archosaurs, and turtles possess a single midline phallus, whereas squamates have paired hemiphalluses (fig. 1). The squamate hemipenis is a blind sac stored in the base of the tail when not erect, creating a diverticulum posterior to the cloaca [Arnold, 1986a, b]. 
Basal birds (paleognaths) and waterfowl (anseriforms) retain a well-developed phallus, although in most birds the phallus is significantly reduced or absent [King, 1981; Briskie and Montgomerie, 1997]. Despite this, internal fertilization is the rule among birds; those lacking an intromittent phallus engage in cloacal apposition for sperm transfer, a behavior known as the cloacal kiss. Only the mammalian phallus contains a closed urethral tube; the phalluses of reptiles instead form an open groove, or sulcus, which functions to channel sperm along the phallus and into the female reproductive tract (fig. 1) [Wake, 1979; King, 1981]. Although squamates have paired phalluses, their closest relatives, the tuataras (Sphenodon), are reported to lack external genitalia and to copulate using cloacal apposition, similar to many bird species (fig. 1) [Robb, 1977; Gans et al., 1984]. It remains unknown whether external genitalia were secondarily lost in tuataras or whether copulatory organs were lost ancestrally in the Lepidosauria [Rhyncocephalia (tuataras) + Squamata] and external genital organs were then re-acquired in squamates.

Despite the shared function of intromittent organs, gross morphology of the amniote penis is quite variable both within and among clades. For example, the glans of the penis in turtles shows extreme morphological variation, ranging from a simple conical tip in sea turtles to an ornate, 5-lobed glans in the soft-shelled turtle Trionyx [Jones, 1915; Zug, 1966]. Similarly, among waterfowl, the phallus varies extensively in length, coiling pattern, and degree of ornamentation [Coker et al., 2002; Brennan et al., 2007]. Like turtles, crocodilians have notable variation in the morphology of the glans [Ziegler and Olbort, 2007; Gredler et al., 2014b]. For many squamate species, each hemipenis assumes a common general plan as a distally bilobed organ with rounded tips, although cylindrical, bulbous, and clavate morphologies have been described [Dowling and Savage, 1960]. Hemipenes are extremely ornate, at times obtaining a medieval weapon-like appearance with barbs, horns, and protuberances [Kluge, 1982; Zaher, 1999; Böhme and Ziegler, 2009]. Much like the mammalian baculum (penis bone), many squamates have evolved skeletal elements that support the hemipenis during copulation [Kluge, 1982; Arnold, 1986a; Shea and Reddacliff, 1986; Böhme, 1988; Card and Kluge, 1995].

Although penile erection can be achieved by multiple mechanisms, the use of hydrostatic pressure is always involved. Most amniotes use blood vasculature for erection, although birds use lymphatics, and the squamate hemipenis utilizes both blood and lymph for inflation [Dowling and Savage, 1960; King, 1981; Arnold, 1986a; Kelly,
$2002,2004]$. In turtles, the open groove of the sulcus functions as a closed tube in copula; erectile tissue becomes engorged with blood, forcing the lateral folds of the sulcus together to create an essentially closed tube [Wake, 1979; King, 1981]. The crocodilian phallus contains a large blood sinus comprised of tissue similar to the erectile vascular tissue in other amniotes, as well as lacunar regions adjacent to the sulcus spermaticus that are believed to function in the formation of a functional tube (urethra) during copulation [Cabrera and Garcia, 2007; Cabrera et al., 2007; Ziegler and Olbort, 2007; Moore et al., 2011, 2012]. The squamate sulcus spermaticus also closes transiently during hemipenile eversion to form a functional tube [Dowling and Savage, 1960].

In many amniotes, erection of the phallus is achieved by muscle contraction in addition to hydrostatic pressure. Anatomical studies have proposed a different mechanism for crocodilia, in which the penis is protruded from the vent by adjacent cloacal musculature; both the sphincter cloacae and levator cloacae muscles have been implicated in this process [Powell, 1999; Kelly, 2013]. In squamates, the transversus penis muscle acts to evert the hemipenes, whereas the retractor penis magnus functions in retraction [Ruiz and Wade, 2002]. Muscle involvement in erection has been similarly described for mammals [Schmidt and Schmidt, 1993] and turtles [Gadow, 1887]. Gadow [1887] reported that the innervation patterns of copulatory anatomical structures are very similar among amniotes, which could suggest a shared evolutionary origin of amniote external genitalia. The mechanisms that orchestrate muscle development in the phallus are largely unknown.

\section{The Reptilian Cloaca}

Development of the phallus is closely associated with morphogenesis of the cloaca. The embryonic cloaca is the common chamber for the urinary, rectal, and genital ducts, and is divided into 3 parts: the coprodeum, urodeum, and proctodeum (fig. 2). The cloacal membrane is a transient epithelial structure formed by fusion of the endoderm and the surface ectoderm of the embryo. Perturbation of cloacal development often disrupts development of the phallus, and a number of human pathologies resulting from disrupted cloacal septation are associated with defects in development of the penis and clitoris [Keppler-Noreuil, 2001; Kim et al., 2001; Perriton et al., 2002; Stoll et al., 2007; Miyagawa et al., 2009; Seifert et al., 2009a; Xu et al., 2012]. 
Fig. 2. Embryonic amniote cloacal anatomy. Schematic drawing of the developing amniote cloaca and external genital swellings. The hindgut connects to the coprodeum, which then empties into the anterior side of the urodeum. The ventral urodeum is connected to the allantois, and the Wolffian duct connects the mesonephric tubules and ureter to the dorsal urodeum. Movement of the urorectal septum is indicated by the curved arrow between the allantois and coprodeum. The cloacal membrane, indicated in red, is formed by fusion of the cloacal endoderm and surface ectoderm. Extension of the cloacal membrane into the base of the genital tubercle forms the sulcus spermaticus in turtles and archosaurs, and the urethra in mammals.

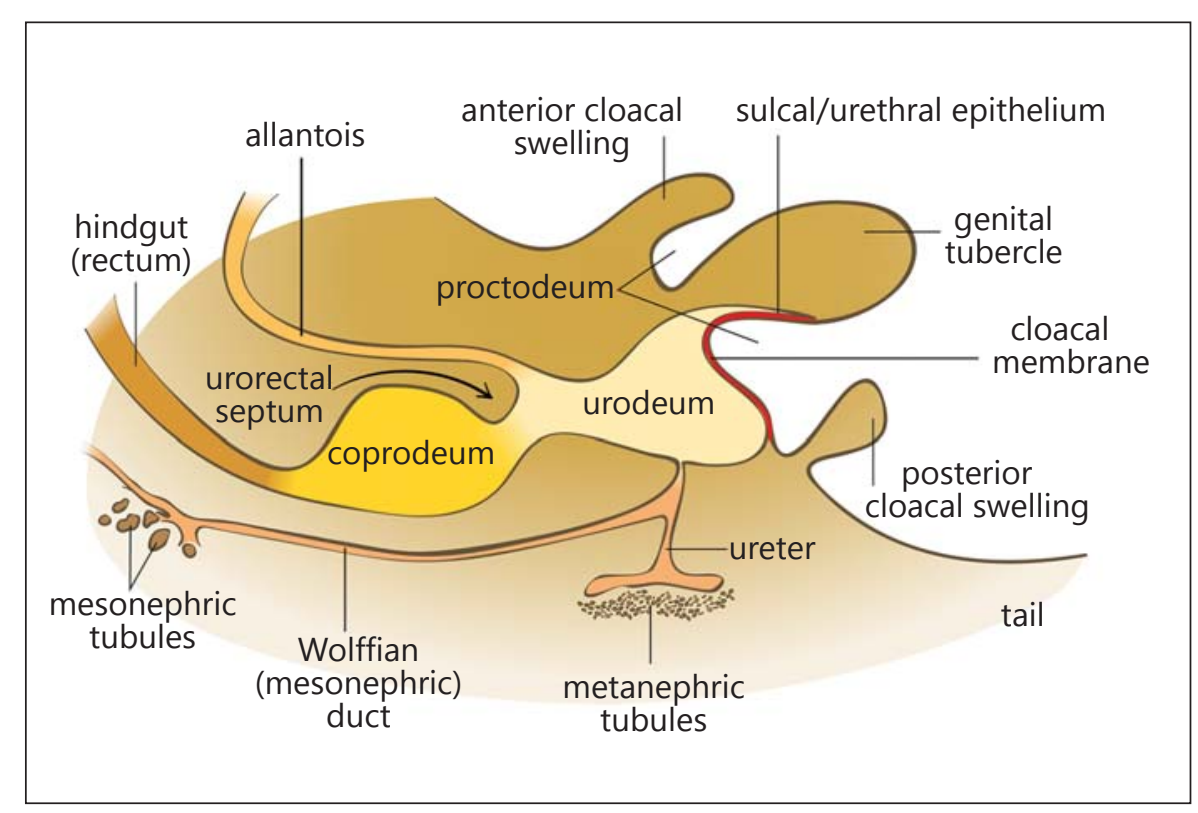

Connections among the Cloacal Chambers, Phallus, Hindgut, and Allantois

The amniote cloaca is regionalized into 3 distinct chambers along its anteroposterior axis (fig. 2). The anterior-most cloacal chamber is the coprodeum, which connects cranially to the rectum by the rectocoprodeal fold and to the urodeum by the coprourodeal fold [Gadow, 1887; King, 1981]. The urodeum develops at the intersection of the allantois and the caudal hindgut, and is connected to the ureter, the bladder (when a bladder is present), and in some cases, the genital ducts. Development of the cloacal lips at the base of the phallus forms the proctodeum, the cloacal chamber that houses the adult phallus/hemiphalluses of archosaurs, turtles, and squamates [Gadow, 1887; Wake, 1979; King, 1981]. Ventral somatopleure (endoderm + the deep layer of lateral plate mesoderm) has been proposed to give rise to both the phallus and the proctodeum in amniotes [Gadow, 1887; Raynaud and Pieau, 1985], although cell lineage of the phallus has not been mapped.

\section{Septation of the Amniote Cloaca}

The urorectal septum forms from mesenchyme overlying the hindgut endoderm (anterior to the urodeum), between the allantois and hindgut (fig. 2) [Kluth et al., 1995]. Posterior expansion of the urorectal septum partitions the cloaca into dorsal and ventral sections; the degree to which this occurs determines the relative size of the unseptated cloaca. In eutherian mammals, the urorectal septum extends all the way to the cloacal membrane, resulting in complete division of the mammalian cloaca into distinct urogenital and anorectal chambers [Kluth et al., 1995; Hynes and Fraher, 2004]. In squamates and birds, there is lateral constriction of the cloacal walls without septation of the embryonic cloaca. In turtles, the embryonic cloaca becomes divided by the urorectal septum into ventral urinary and dorsal rectal canals, with the urorectal septum reaching the base of the developing phallus. However, this septation is not as extensive as in eutherian mammals, and the adult phallus and rectal orifices are housed within the proctodeum [Raynaud and Pieau, 1985; Larkins and Cohn, 2014].

\section{Development of the External Genitalia}

\section{Turtle Phallus}

Phallus development in the male turtle has been described for the Greek tortoise Testudo graeca, the European pond turtle Emys orbicularis, and for the red-eared slider Trachemys scripta [Raynaud and Pieau, 1985; Larkins and Cohn, 2014]. In these turtle species, development of the phallus begins at the early limb bud stage with emergence of a pair of genital swellings on the ventral body wall adjacent to a median ridge that contains the cloacal membrane (fig. 3A). The genital swellings and median ridge grow distally from the body wall to form a single genital tubercle, the anlage of the phallus (fig. 3B). 

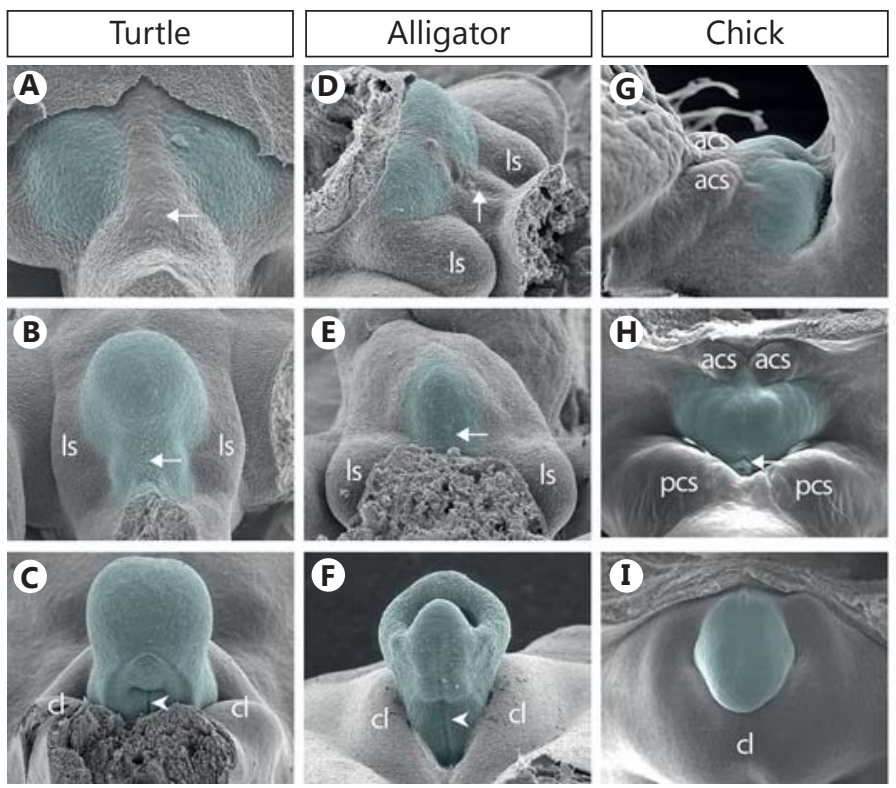

Fig. 3. Scanning electron micrographs of amniote external genital development. Morphogenesis of amniote external genitalia at 3 approximately equivalent stages of development. All SEMs are ventral views and anterior is at the top, except for $\mathbf{D}$ and $\mathbf{G}$, which are lateral views with anterior to the left. The developing phallus is pseudocolored green in all panels. A-C Trachemys scripta (redeared slider turtle), D-F Alligator mississippiensis (American alligator), G-I Gallus gallus (chicken), J-L Anolis carolinensis (green anole), M-O Python regius (ball python), P-R Mus musculus (mouse). Top row (A, D, G, J, M, P): Genital swelling stage, early in external genitalia development. Middle row $(\mathbf{B}, \mathbf{E}, \mathbf{H}, \mathbf{K}, \mathbf{N}, \mathbf{Q})$ : Genital tubercle or hemiphallus buds present. Bottom row $(\mathbf{C}, \mathbf{F}, \mathbf{I}, \mathbf{L}$,

The cloacal membrane is found at the ventral midline of the developing phallus. As the tubercle grows, lateral cloacal swellings form at the base of the genital tubercle and will become the adult cloacal lips (fig. 3B, C) [Raynaud and Pieau, 1985; Larkins and Cohn, 2014]. The ventral bending of the embryo pushes the tail into close proximity with the tubercle, such that the ventral surface of the tail abuts the ventral side of the genital tubercle. This movement, together with growth of the cloacal lips, results in only the most distal part of the phallus being visible (fig. 3C) [Raynaud and Pieau, 1985; Larkins and Cohn, 2014]. By this point, the cloacal membrane has ruptured to reveal the urethral sulcus (fig. $3 \mathrm{C}$ ). The cloacal lips continue to grow until the phallus is completely engulfed, creating the most posterior region of the adult cloaca, the proctodeum [Raynaud and Pieau, 1985; Larkins and Cohn, 2014]. As adults, different turtle species have distinct elaborations of their glans, such as various assemblies of folds, lobes, and grooves, but given the

Reptilian External Genital Development and Evolution
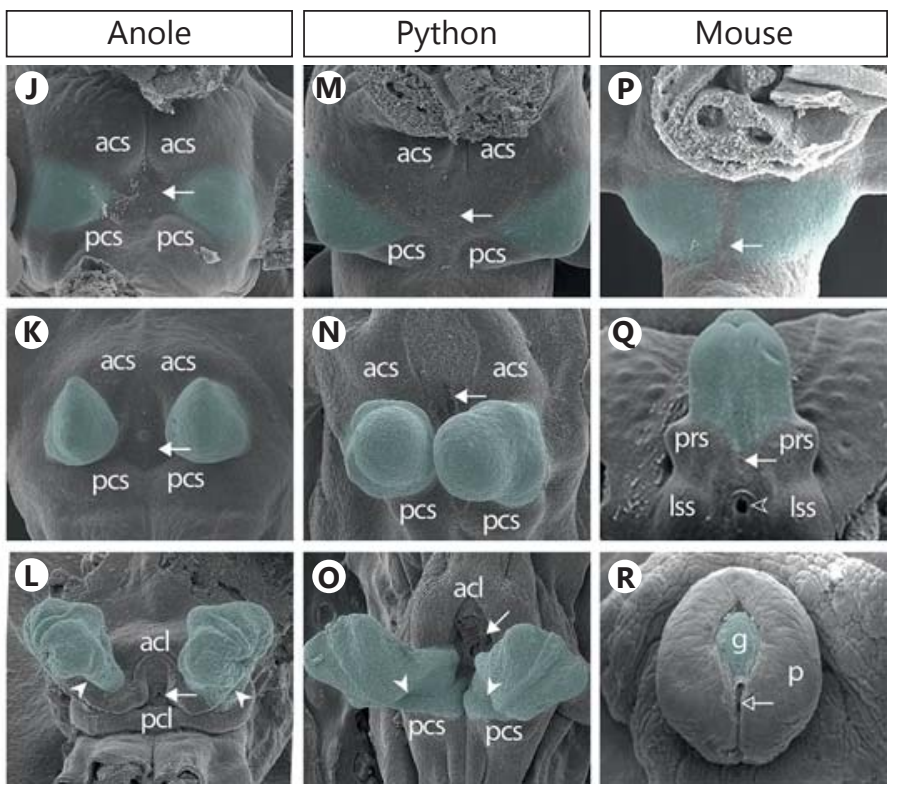

O, R): Late genital tubercle or hemiphallus stage. Developmental series have been published for Trachemys scripta [Larkins and Cohn , 2014], Alligator mississippiensis [Gredler et al., 2014b], Gallus gallus [Herrera et al., 2013], Anolis carolinensis [Gredler et al., 2014a], Python regius [Leal and Cohn, 2014], and Mus musculus [Perriton et al., 2002]. White arrows indicate the cloacal membrane; white arrowheads indicate the sulcus spermaticus; open arrowhead indicates the proximal urethral opening; open arrow indicates the urethral meatus. acl = Anterior cloacal lip; acs = anterior cloacal swelling; $\mathrm{cl}=$ cloacal lip; $\mathrm{g}$ = glans; ls = lateral swelling; lss = labioscrotal swelling; $\mathrm{p}=$ prepuce; $\mathrm{pcl}$ = posterior cloacal lip; pcs = posterior cloacal swelling; prs = preputial swellings.

broad conservation of early genital development across amniotes, it seems likely that all turtles begin phallic development in the same basic manner [Zug, 1966]. Understanding how different testudine species generate their distinctive glans morphologies will require further comparative studies of external genital development.

Although sex determination is temperature-dependent in turtles, the response of external genitalia to temperature and sexual differentiation depends on hormones. The penis of male turtles and the clitoris of females are structurally similar with the exception of the female phallus being much smaller than that of the male [Jones, 1915]. Most of the work regarding hormonal regulation of turtle development has examined development of the gonads, but androgen likely has a role in development of the phenotypically male phallus, as androgen exposure in turtles causes accelerated growth and hypertrophy of the phallus [Wibbels and Crews, 1992; Crews et al., 1995; Crespo et al., 2013]. The role of estrogen in regu- 
lating development of the phallus is not clear, although estrogen is required for development of the ovary, and estrogen production may be upregulated in response to female-producing temperatures [Wibbels et al., 1991; Bergeron et al., 1999]. Examination of the phallus in androgen- or estrogen-treated turtles will be important to determine the role of hormones in turtle external genital development.

\section{Crocodilian Phallus}

Although gonadogenesis has been intensively investigated in alligators and crocodiles [Forbes, 1940; Ferguson, 1985; Smith and Joss, 1993, 1995; Smith et al., 1995; Western et al., 1999, 2000], few studies have investigated early development of the crocodilian phallus [Gadow, 1887; Reese, 1915, 1924; Ferguson, 1985]. Early development of external genitalia in alligators is similar to other amniotes [Gadow, 1887; King, 1981; Ferguson, 1985; Gredler et al., 2014b; Larkins and Cohn, 2014]. Genital swellings emerge between the hindlimb buds, on either side of the cloacal membrane, at an early stage of development (fig. 3D). The genital swellings later form the genital tubercle (fig. 3D, E). Outgrowth of the genital tubercle and formation of the phallic ridge regionalizes the embryonic phallus into the phallic ridge (or cuff), glans (or tip), and shaft (or base) (fig. 3F). Simultaneous development of the cloaca occurs by interaction between the posterior limits of the digestive and excretory tracts [Gadow, 1887; Ferguson, 1985; Gredler et al., 2014b].

Sexual differentiation of crocodilian genitalia is sensitive to environmental signals in addition to temperature. Environmental endocrine disrupting chemicals, for example, have been shown to have profound effects on gonadal and external genital development in American alligators (A. mississippiensis). For example, a negative correlation between penis size and exposure to endocrine disrupting contaminants has been found in alligators living in contaminated environments [Guillette et al., 1994, 1995, 1996, 1999; Gunderson et al., 2004]. The molecular mechanisms that mediate the effects of these chemicals on external genital development are not well understood, although recent gene expression analyses have identified potential targets of exogenous compounds in the embryonic crocodilian phallus [Gredler et al., 2014b].

\section{Avian Phallus}

Basal birds (paleognaths) have retained the phallus, and waterfowl have dramatically increased phallus size, coiling, and ornamentation. Most birds, however, have undergone extreme reduction or complete loss of the phallus, such that approximately $97 \%$ of extant bird species lack an intromittent organ altogether [Briskie and Montgomerie, 1997; Brennan and Prum, 2012]. Recent studies have shed light on the developmental and molecular foundations of phallic reduction in birds [Herrera et al., 2013, 2014]. Development of the phallus has been described for species with varying degrees of external genital outgrowth, ranging from the elaborate phalluses of ducks to the rudimentary non-intromittent phalluses of chickens. At early stages, the intromittent phallus of anseriforms (waterfowl) and the non-intromittent phallus of galliforms (chickens and other land fowl) are very similar [Bakst, 1986; Bakst and Cecil, 1986; Herrera et al., $2013,2014]$. The external genitalia begin to form when the paired genital swellings emerge on either side of the cloacal membrane (fig. 3G). Two additional pairs of swellings, the anterior and posterior cloacal swellings, give rise to the cloacal collar (fig. 3G, H). The paired genital swellings fuse to form the genital tubercle, and cloacal swellings fuse to form the anterior and posterior cloacal lips (later these lips fuse to form the cloacal collar [Herrera et al., 2013]) (fig. 3I). The genital tubercles of galliforms then arrest and regress, leaving only a rudimentary phallic swelling [Herrera et al., 2013, 2014]. Development of the genital tubercle continues in ducks and geese, eventually taking on a spiral pattern of outgrowth that underlies the coiled morphology seen in adult males [Herrera et al., 2014]. Sexual differentiation of duck external genitalia occurs at relatively late stages, just prior to hatching, whereas in chickens, sexual dimorphism of the phallus diminishes over developmental time and is not apparent after hatching. Although phallus morphology is highly variable among different species of ducks, comparative analysis of external genital development across 3 duck species with variable adult morphologies showed little difference in genital form even at late stages of development, suggesting that the variation arises post-hatching [Herrera et al., 2014].

It has long been known that avian phallus morphology (as well as testes and bursa size) undergoes transient changes during the breeding season and in response to female stimuli [Briskie and Montgomerie, 1997]. The mechanisms by which sex hormones shape development of avian genital structures are not well understood. Hormone levels in yolk, plasma, and in the embryo have been characterized, and these studies can serve as a platform for investigating interactions between sex steroids and the genetic pathways that sculpt avian external genital structures [Woods et al., 1975; Sayag et al., 1991; Henry and Burke, 1999; Katoh et al., 2006]. 
Squamate Hemipenes and Hemiclitores

Squamates develop paired copulatory organs called hemipenes (male) and hemiclitores (female) [Gadow, 1887; King, 1981; Lombardi, 1998; Kardong, 2012]. The most comprehensive studies of early development of the hemipenes in squamates were done by Raynaud and Pieau [1970, 1985] in the European green lizard (Lacerta viridis), slow-worm serpentiform lizard (Anguis fragilis), and the dice snake (Natrix tessellata). Little work has been done on hemipenes development since the publication of these classical descriptions, although 2 recent studies have characterized the embryology and the cellular and molecular development of hemipenes in the green anole, Anolis carolinensis [Gredler et al., 2014a] and the ball python, Python regius [Leal and Cohn, 2014].

Morphogenesis of the hemipenes and hemiclitores is generally conserved across different lineages of lizards and snakes but differs from development of the single amniote genital tubercle in a number of ways [Raynaud and Pieau, 1985; Gredler et al., 2014a; Leal and Cohn, 2014]. Major differences between squamate and nonsquamate amniote external genital development include the paired nature of the hemiphalluses, their embryonic origin relative to the hindlimb buds and cloacal membrane, and the molecular mechanisms underlying formation of the sulcus spermaticus [Raynaud and Pieau, 1985; Gredler et al., 2014a; Leal and Cohn, 2014].

Like other amniotes, squamate embryos develop iterative pairs of swellings around the cloacal membrane (fig. 3J, M) [Raynaud and Pieau, 1985; Gredler et al., 2014a; Leal and Cohn, 2014]. At least 3 pairs of external genital/cloacal swellings form along the lateral edges of the cloaca. Based on their anatomical positions (rather than inferences of homology), these are termed the anterior cloacal swellings, hemiphallus swellings, and posterior cloacal swellings (fig. 3J, M). These swellings give rise to the anterior lip of the cloaca, the hemiphalluses, and the posterior lips of the cloaca, respectively [Raynaud and Pieau, 1985; Gredler et al., 2014a; Leal and Cohn, 2014]. Although the bilateral anterior and posterior cloacal swellings fuse to form the anterior and posterior lips of the cloaca, the hemiphallus swellings emerge lateral and posterior to the cloacal membrane and remain adjacent (and sometimes posterior) to the cloacal membrane as each one differentiates into a hemiphallus (hemipenis or hemiclitoris) [Raynaud and Pieau, 1985; Gredler et al., 2014a; Leal and Cohn, 2014].

In squamates, genital swelling initiation occurs in close proximity to the early hindlimb buds [Raynaud and Pieau, 1970, 1985; Rosenberg et al., 1989; Leal and Cohn, 2014]. In the green anole, the hemiphallus swellings originate at

Reptilian External Genital Development and Evolution the base of the hindlimb buds, on the postero-ventral surface (fig. 3J) [Gredler et al., 2014a], while in other amniotes the phallus swellings develop medial to the hindlimb buds, closer to the cloacal membrane (fig. 3) [Raynaud and Pieau, 1985; Gredler et al., 2014b; Herrera et al., 2014; Larkins and Cohn, 2014; Leal and Cohn, 2014]. The topographic association between the hindlimb buds and hemiphallus swellings in the green anole does not necessarily indicate a mechanistic or causal link between limb and genital development, as limbless squamates that show no signs of embryonic hindlimb buds nonetheless conserve fully developed hemipenes [Raynaud and Pieau, 1970, 1985]. This implies that the hemipenes and hindlimbs are dissociable structures in both development and evolution. However, it is plausible that the hemipenes and limbs come from a common or adjacent population(s) of cells derived from the lateral plate mesoderm [Gredler et al., 2014a]. Interestingly, an association between the limbs and embryonic cloaca would not be unique to squamates, since it has been found that muscle precursor cells in the chicken hindlimbs and cloaca are derived from a common population of cells [Valasek et al., 2005]. In the chick, cloacal muscle cells are derived from axially located somites, which migrate to the proximal hindlimb bud and then can be identified as discrete regions of MyoD-positive cells that later split, with one subpopulation forming the hindlimb muscle and the other migrating back out of the limb to form the cloacal muscle [Valasek et al., 2005].

The hemiphallus swellings of squamates do not extend medially over the cloacal membrane, but instead remain separate from one another in a lateral position [Raynaud and Pieau, 1985; Gredler et al., 2014a; Leal and Cohn, 2014]. In other amniotes, medial fusion of the paired genital swellings is a key developmental event that forms the single midline phallus, and may be essential for the incorporation of endoderm into the phallus, either as a sulcus spermaticus or as a tubular urethra [Perriton et al., 2002; Cohn, 2011]. Squamates do not undergo fusion of the hemiphallus swellings, and the hemipenes develop without an endodermal contribution [Raynaud and Pieau, 1985; Gredler et al., 2014a; Leal and Cohn, 2014]. Each hemipenis later develops a seminal furrow, called the sulcus spermaticus, which is formed by invagination of surface ectoderm along the medial surface of each hemipenis bud (fig. 3L, O) [Raynaud and Pieau, 1985; Gredler et al., 2014a; Leal and Cohn, 2014]. Thus, the sulcus spermaticus of squamates has a different embryonic origin (ectoderm) from that of turtles, archosaurs, and mammals (endoderm; discussed below) [Perriton et al., 2002; Seifert et al., 2008; Cohn, 2011; Herrera et al., 2013, 2014; Gredler et al., 2014a, b; Larkins and Cohn, 
2014; Leal and Cohn, 2014]. The unusual development of squamate hemiphalluses, particularly the absence of an endodermal epithelium, a key signaling region in the genital tubercles of other amniotes [Perriton et al., 2002; Seifert et al., 2008, 2010], suggests that at least some of the fundamental mechanisms of external genital development have undergone evolutionary modifications in squamates.

Sexual differentiation of the hemipenes and hemiclitores occurs late in development [Raynaud and Pieau, 1985; Gredler et al., 2014a]. In general, hemiphalluses develop similarly in male and female squamates until after formation of the sulcus spermaticus, when the female buds start to regress to a vestigial state [Raynaud and Pieau, 1985; Gredler et al., 2014a]. Experimental manipulations have shown that androgen and estrogen levels are important for sexually dimorphic development of squamate external genitalia [Raynaud and Pieau, 1985; Holmes and Wade, 2005; Rhen et al., 2005; Beck and Wade, 2008]. Steroid hormone receptors are expressed dimorphically during external genital development in Anolis; embryonic hemipenes have high expression of androgen receptor whereas female hemiclitores express high levels of estrogen receptor alpha [Raynaud and Pieau, 1985; Holmes and Wade, 2005; Rhen et al., 2005; Beck and Wade, 2008]. This is consistent with the temporal correlation between ovary development and hemiphallus bud regression to form the female hemiclitores [Raynaud and Pieau, 1985; Holmes and Wade, 2005; Rhen et al., 2005; Beck and Wade, 2008]. Thus, the variation in relative timing of gonadal development in squamates could explain the variation in external genital dimorphism [Raynaud and Pieau, 1985; Holmes and Wade, 2005; Rhen et al., 2005; Beck and Wade, 2008]. It is noteworthy that recent studies in the mouse have shown that estrogen is required to inhibit growth of the clitoris [Yang et al., 2010], which raises the possibility that a common mechanism may be involved in feminization of the phallus across amniotes.

\section{Ontogeny of the Reptilian Sulcus}

Despite the common function of the sulcus and urethra, these structures differ significantly between mammals and other amniotes. Mammals have a closed urethral tube but all other amniotes have an open urethral groove or sulcus (figs. 1, 2). In mammals, turtles, alligators, and birds, the sulcal/urethral epithelium is derived from cloacal endoderm [Wake, 1979; King, 1981; Raynaud and Pieau, 1985]. Genital swellings emerge on either side of the cloacal membrane and fuse at the midline to form the genital tubercle. When the paired swellings merge to form the genital tubercle, the ventral wall of the cloaca becomes incorporated into the center of the tubercle and, as the tubercle grows distally, the cloacally derived endoderm forms a bilaminar sulcal or urethral plate along the posterior/ventral side of the growing phallus. In turtles, alligators, birds, and some mammals, the cloacal membrane ruptures along the ventral margin of the phallus, which results in an open sulcus or urethral groove [Wake, 1979; King, 1981; Raynaud and Pieau, 1985; Gredler et al., 2014b; Herrera et al., 2014; Larkins and Cohn, 2014]. This open urethral groove is maintained in non-mammalian amniotes. In mammals, the urethral plate either remains closed at the ventral seam (as in rodents) or ruptures and then closes by fusion of the urogenital folds (as in humans) [Kurzrock et al., 2000].

Development of the sulcus in squamates differs significantly from all other amniotes. The squamate cloacal membrane forms as it does in other amniotes; however, it is maintained in its initial position at the surface of the ventral body wall, while the genital swellings of the hemipenes grow distally on either side, without fusing at the midline [Raynaud and Pieau, 1985; Gredler et al., 2014a; Leal and Cohn, 2014]. At later stages of hemiphallus development, ectodermal invaginations form along the proximal-distal axis of each hemiphallus, generating the sulcus spermaticus [Gredler et al., 2014a; Leal and Cohn, 2014]. The cloacal membrane ruptures on the surface of the ventral body, and the ectodermal sulci become contiguous with the cloacal opening. Thus, the squamate sulcus is derived from surface ectoderm of each hemipenis, and the cloacal endoderm is not incorporated into the phallus. Since the sulcus/urethra of all other amniotes develops from endoderm, an ectodermally derived sulcus spermaticus must have been acquired independently in squamates. It is possible that medial fusion of the genital swellings in non-squamate amniotes is required for incorporation of the cloacal endoderm into the phallus and, therefore, failure of hemipenes to fuse medially may account for the absence of cloacal endoderm in squamate genitalia.

\section{Molecular Mechanisms of External Genital Morphogenesis}

Major progress in our understanding of the molecular mechanisms of external genital development has been made over the past 10-15 years. Most of these advances have come from the mouse model, due to its well-characterized development, sequenced genome, and accessibility for genetic and genomic manipulation [for details, see 
review by Cohn, 2011; Ipulan et al., this issue]. The identification of signaling pathways that play important roles in development of mammalian external genitalia has begun to establish a foundation for comparative studies. Below, we review some recent progress in understanding the mechanisms involved in the evolution of genital development in birds and reptiles. It is noteworthy that only a handful of studies have been conducted in these taxa, and there are numerous questions that remain unaddressed. These gaps present exciting opportunities and challenges for future investigation.

In the developing external genitalia, many genes are expressed in similar patterns across different amniote clades [Perriton et al., 2002; Herrera et al., 2013, 2014; Gredler et al., 2014a, b; Larkins and Cohn, 2014; Leal and Cohn, 2014]. For example, all amniotes express Hoxd13 in the phallic anlage and, with the exception of squamates, show expression of Shh in the sulcus/urethral epithelium and Ptch1 expression in the adjacent mesenchyme. However, differences in gene expression of important signaling molecules (such as Bmp4 and its downstream target, $M s x 2$, which mediate many developmental processes, including apoptosis) may be associated with gross anatomical differences in external genital morphology within and among amniote clades.

\section{Bmp Signaling and Variation in External Genital \\ Structures}

The arrest and regression of the galliform genital tubercle is caused by BMP4-mediated apoptosis at the distal tip of the genital tubercle [Herrera et al., 2013]. The distal domain of Bmp4 expression that occurs in galliform genitalia is absent from the genital tubercles of ducks and emus, both of which form well-developed intromittent phalluses. Inhibition of Bmp signaling by experimental application of Noggin protein (a Bmp antagonist) can restore cell survival and increase outgrowth in chick genital tubercles [Herrera et al., 2013]. Furthermore, application of BMP2 protein (which signals via the same receptor as BMP4) to the distal tip of duck genital tubercles is sufficient to induce ectopic cell death, indicating that Bmp activity is necessary and sufficient for apoptosis-mediated regression of the genital tubercle in birds [Herrera et al., 2013].

Multiple anatomical structures that show variation among amniote external genitalia have been demonstrated to be associated with modulation of Bmp expression domains. Bmp4 is normally found in the mesenchyme adjacent to the urethra in the mouse, however in turtle and alligator, $B m p 4$ is also expressed along the ventral seam of the cloacal membrane and sulcus prior to it rupturing [Perriton et al., 2002; Suzuki et al., 2003; Gredler et al., 2014b; Larkins and Cohn, 2014]. The same is true for the Bmp target gene $M s x 2$, which is also expressed along the cloacal membrane and in the sulcus. Bmp signaling induces apoptosis in many developmental contexts [Suzuki et al., 2003; Bandyopadhyay et al., 2006; Herrera et al., 2013] and, consistent with this, apoptosis is found along the turtle and alligator cloacal membranes just prior to their rupture [Gredler et al., 2014b; Larkins and Cohn, 2014]. These results suggest that Bmp signaling and apoptosis may be required for generation of the urethral groove of the sulcus spermaticus. Experimental inhibition of Bmp signaling and/or apoptosis in turtle and alligator embryos should determine the role of this signaling pathway in sulcus development.

In contrast to turtles and crocodilians, formation of the sulcus spermaticus in pythons is not associated with Bmp4 or Msx2 expression [Leal and Cohn, 2014]. However, $B m p 4$ and $M s \times 2$ are both expressed at the distal tip of the developing hemipenes. Bmp4 is also expressed in the cloacal endoderm. Whether Bmp signaling is essential for the cloaca rupture in squamates remains to be tested [Gredler et al., 2014a; Leal and Cohn, 2014]. Similarly, it is not clear whether birds have Bmp4 expression along the cloacal membrane prior to its rupture. It is noteworthy that the mouse genital tubercle lacks expression of $B m p 4$ or $M s \times 2$ along the length of the cloacal membrane or urethral epithelium, and these tissues do not undergo extensive apoptosis, with the exception of the most proximal and distal regions [Perriton et al., 2002; Suzuki et al., 2003; Lin et al., 2009]. Moreover, mice do not exhibit degradation of the ventral epithelium along the entire proximal-distal axis of the genital tubercle, as is the case in other mammals such as rabbits, pigs, and humans [Glenister, 1956; Paidas et al., 1999; Kurzrock et al., 2000]. This could mean that upregulation of Bmp signaling and apoptosis along the ventral surface of the genital tubercle is an event that normally occurs in some mammals, such as humans, to generate the urogenital ostium, and that hypospadias is caused by the failure to close this ostium at later stages. Examination and manipulation of Bmp signaling and apoptosis in mammals that form an ostium should determine whether epithelial degradation along the ventral surface of the genital tubercle occurs similarly to turtles and alligators.

\section{Genetic Regulation of Hemiphallus Development}

Analyses of gene expression in developing hemipenes have been conducted in green anole and ball python embryos [Gredler et al., 2014a; Leal and Cohn, 2014]. These studies revealed both conserved and divergent expression patterns of developmental genes. One of the major differ- 
ences is that early hemiphallus buds lack hedgehog signaling, whereas all other amniotes show strong expression of Shh in the urethral/sulcus epithelium of the genital tubercle [Gredler et al., 2014a; Leal and Cohn, 2014]. In the mouse, Shh expression in the urethral epithelium acts as a proliferative, survival, and polarizing factor to drive outgrowth and patterning of the genital tubercle [Perriton et al., 2002; Seifert et al., 2009a, 2010]. The absence of Shh and Ptch1 (a readout of Shh signal transduction) expression in the developing hemipenes, together with histological data, suggests that squamates lack an equivalent endodermally derived external genital organizer. Likewise, the expression patterns of other genes associated with endodermal urethral/sulcus epithelium (i.e. Fgfr2 and Fgf8) and the surrounding mesenchyme (i.e. Fgf10 and Bmp4) are different in squamates. The observations that $S h h$, $\mathrm{Fg} f \mathrm{r} 2$, and $\mathrm{Fg} 8 \mathrm{~d}$ are not detectable in the squamate sulcus spermaticus further support the non-equivalence of the squamate sulcus spermaticus and the amniote sulcus/urethra [Gredler et al., 2014a; Leal and Cohn, 2014].

With the exception of the differences described above, squamate hemipenes express a battery of genes associated with appendage growth, illustrating conserved expression patterns among amniote genital tubercles [Gredler et al., 2014a; Leal and Cohn, 2014]. These genes are expressed at either the distal tip, such as Wnt5a, Bmp4, Msx2, and Hoxa13, or throughout the genital swellings, such as $T b \times 4$ and Hoxd13 [Leal and Cohn, 2014]. It is possible that the expression patterns of these developmental genes in external genital swellings are shared between squamates and the other amniotes due to independent co-option of the genetic program for appendage development, rather than reflecting structural homology of hemipenes and penises of other amniotes. Nonetheless, molecular development of squamate external genitalia has been examined in only 2 species thus far, and further studies are needed to resolve the question of homology of squamate hemipenes to the single midline phallus in non-squamate amniotes.

\section{The Reptilian Sulcus: Insights into Hypospadias}

\section{Hypospadias as a Primitive Condition}

One of the most common birth defects in humans is a failure to form a fully closed urethral tube, a condition known as hypospadias. Hypospadias can range from a small ectopic opening of the urethra anywhere along the penis (from the glans to the perineum) to a complete failure of urethral tube closure along the entire ventral side of the phallus. The causes of hypospadias are still under in- vestigation, but experimental and clinical evidence indicates that it can result from environmental causes, genetic factors, or both [reviewed in Blaschko et al., 2012]. For example, hypospadias is commonly found in patients with hand-foot-genital syndrome, which results from a mutation in HOXA13 [Mortlock and Innis, 1997]. In addition, embryonic exposure to environmental contaminants that block androgen signaling can lead to hypospadias [Paulozzi et al., 1997; Yiee and Baskin, 2010]. While some of the genetic causes of hypospadias are known, most are not, and it is not clear which genetic targets act downstream of endocrine disrupting effectors. Because the hypospadias condition can be remarkably similar to what is found naturally in non-mammalian amniotes, comparing mammalian and non-mammalian urethral development may give us insight into the events that led to the evolutionary transition from an open urethral sulcus to a closed urethral tube, and how these events can be disrupted to generate hypospadias. In the contexts of both phylogeny and developmental mechanisms, the persistence of an open urethral groove in severe hypospadias could be interpreted as a reversion to the primitive amniote condition of having an open sulcus rather than a closed tube.

\section{Ontogeny and Molecular Genetic Control of Cloacal Septation}

Another feature that differs between mammalian and non-mammalian anogenital sinuses, which may contribute to a closed versus open urethra, is the degree of cloacal septation. The urorectal septum in mammals separates the anorectal and urogenital sinuses, forms the perineum, and then extends into the phallus, where it internalizes the male urethra [Hynes and Fraher, 2004; Seifert et al., 2008]. Nonmammalian amniotes do not undergo complete septation of the cloaca, nor does the septum invade the phallus. If closure and internalization of the urethral tube is dependent upon growth of the urorectal septum into the phallus [Seifert et al., 2008], then it is possible that the absence of cloacal septation in non-mammalian amniotes plays a role in the persistence of a sulcus. In support of this, hypospadias is often found in mouse mutants and humans that show defective cloacal septation [Metts et al., 1997; Garcia et al., 2006; Yucel et al., 2007; Seifert et al., 2009a; Wu et al., 2009]. Another possibility is that the genes that regulate cloacal septation are also responsible for closure and internalization of the urethra. For example, in mice, Shh is required for cloacal septation and for maintenance of the closed urethral tube, with the null Shh mutant lacking external genitalia and having persistent cloaca [Haraguchi et al., 2001; Perriton et al., 2002]. Conditional deletion of Shh 
after the completion of cloacal septation results in hypospadias that ranges in severity according to the timing of Shh deletion [Lin et al., 2009; Seifert et al., 2009a]. It will be interesting to carefully examine not only the patterns but also the levels of gene expression that are important for cloacal septation in non-mammalian amniotes. It may stand to reason that in order to fully understand urethral tubulogenesis, we must understand cloacal septation and growth of the urorectal septum in both mammals and non-mammals.

\section{The Evolution of External Genital Development: Resolving the Question of Homology}

Internal fertilization is necessary for development of the amniotic egg and, therefore, a mechanism of sperm transfer must have been present in the common ancestor of amniotes [Romer and Parsons, 1986]. Whether primitive amniotes copulated using a phallus or through cloacal apposition, similar to tuataras [Gans et al., 1984] and many birds [Briskie and Montgomerie, 1997], remains uncertain. Based on the phylogenetic distribution of intromittent phalluses, their similar embryonic origins across amniotes, and the conservation of cellular and molecular mechanisms of development, we favor the hypothesis that a single midline phallus with an endodermal sulcus spermaticus was present in the common ancestor of amniotes, and a closed urethral tube evolved in the mammalian lineage (fig. 4A). According to this hypothesis, the endodermal sulcus was lost and an ectodermal sulcus was gained in squamates. Nonetheless, we recognize that there are at least 3 alternative evolutionary scenarios that could explain the phylogenetic distribution of phalluses in amniotes: (1) A single midline phallus with an endodermal urethral tube (rather than a sulcus, as proposed above) was present in the common ancestor of amniotes (fig. 4B). In this scenario, the endodermal urethral tube would have formed an open sulcus in the common ancestor of non-squamate reptiles, and the midline phallus and phallic endoderm would have been completely lost in Squamata. (2) All amniote phalluses are derived from paired genital swellings; however, the midline phallus evolved independently in mammals and non-squamate reptiles (fig. 4C). (3) Paired genital swellings and the clade-specific intromittent organs evolved independently in squamates, archosaurs, and mammals (fig. 4D). Although our preferred hypothesis is based on developmental evidence available to date, and none of these 3 alternatives offer more parsimonious explanations, there are aspects of each scenario that warrant further investigation.

Reptilian External Genital Development and Evolution
Development often has been used to resolve questions regarding anatomical homology when secondary divergence poses challenges to direct comparisons of the adult structures [Wagner, 1994; Raff, 1996]. As discussed above, there are significant anatomical differences in the adult phalluses of amniotes. However, similarities in the genetic programs underlying external genital morphogenesis now shed new light on the debate regarding the evolution of the amniote phallus. Importantly, the phalluses of most, if not all, amniote groups begin as paired swellings within a presumptive genital field surrounding the cloaca. In mammals, turtles, and archosaurs, these paired swellings fuse to form a single, midline phallus with contributions from all 3 embryological germ layers. Despite differences in the origin of the spermatic sulcus, squamate hemipenes also develop from the direct expansion of paired genital swellings in the embryo. These observations are consistent with an intromittent phallus being a shared, derived character of amniotes. Given that tuataras have been reported to lack intromittent phallus(es), this interpretation also raises additional questions regarding the specific evolutionary steps that led to the origin of squamate hemipenes. Whether the ancestors of tuataras (or the common ancestor of tuataras and squamates) possessed a single or paired phallus remains unknown. Nonetheless, our interpretation of phallus evolution suggests that hemipenes evolved through significant modification of a more widely shared ancestral developmental program.

Absence of a phallus in most extant amphibians raises the possibility that the evolutionary origin of the phallus occurred near the base of Amniota. Another intriguing possibility, however, is that the phallus arose prior to amniotes, near the origin of tetrapods, and was subsequently lost in frogs and salamanders [Gauthier et al., 1988]. The third group of modern amphibians, caecilians, possesses a single, midline, male-specific intromittent organ, the phallodeum, which has long been considered convergent with the amniote phallus [Wake, 1972; Gauthier et al., 1988]. Detailed comparative analysis of caecilian cloaca and phallus development has the potential to further advance our understanding of vertebrate genital evolution.

\section{Prospectus}

Developmental studies of non-mammalian amniotes have significantly expanded in recent years. These studies have brought new perspectives to our understanding of developmental mechanisms, diversity, and evolution, 


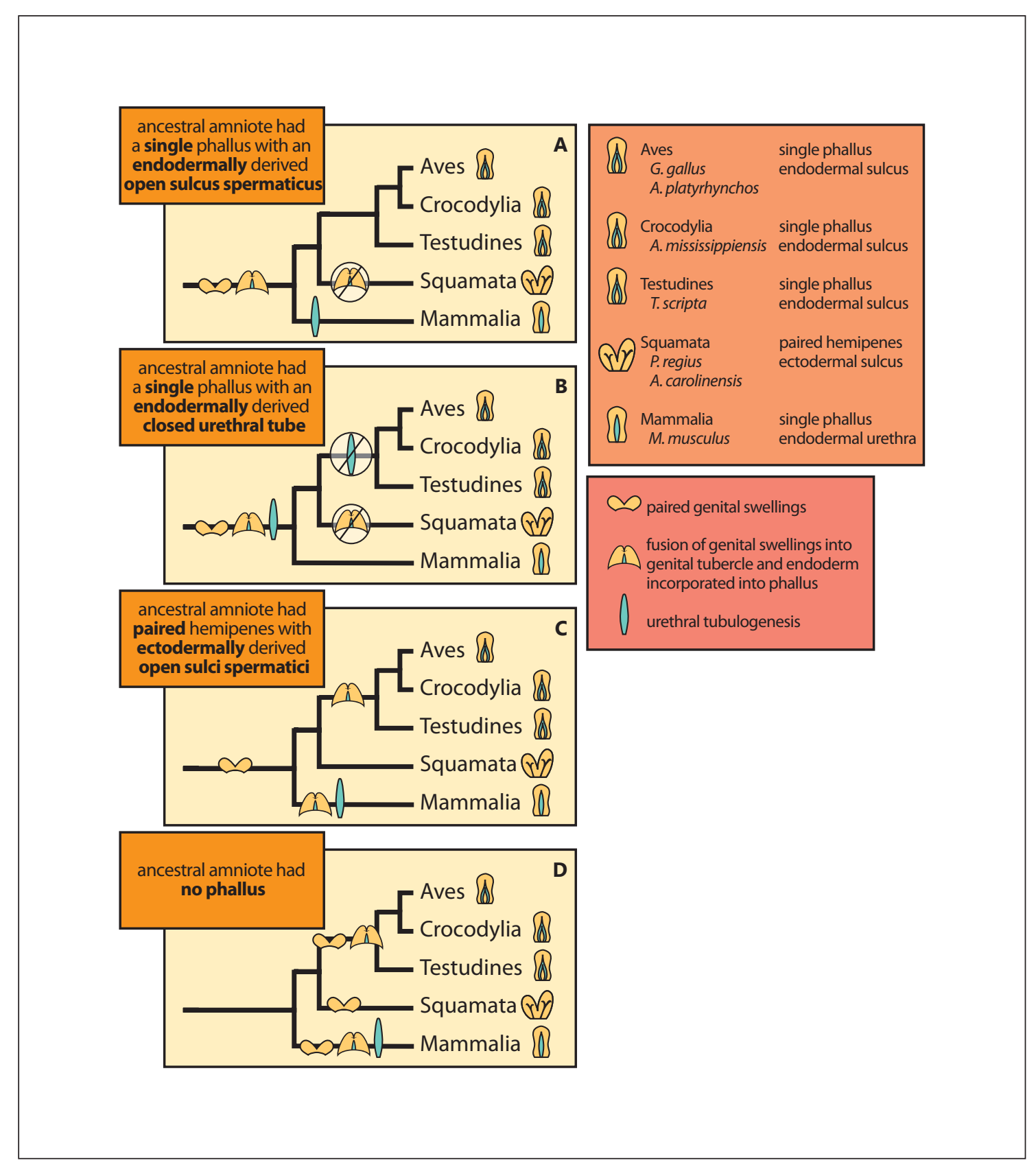

Fig. 4. A-D Alternative scenarios for the evolution of amniote external genital morphogenesis. Each phylogeny shows one series of evolutionary transitions that can explain the morphological diversity of amniote external genitalia and the developmental mechanisms required for these character states. Three characters of external genital development are shown (pink box), each with 2 character states. The characters are phallus number (paired or single), phallic endoderm (presence or absence), sulcus morphology (open sulcus spermaticus or closed urethral tube), and the developmental origin of sulcus/urethral epithelium (endoderm or ectoderm). Scenario $\mathbf{A}$ reconstructs the series of events by which the suite of external genital characters that are present in extant reptiles could have evolved from a common amniote ancestor that had a single phallus with an endodermally derived open sulcus spermaticus, or an archosaur/turtle pattern. B reconstructs the evolution of these characters from an ancestral state of the mammalian pattern, a single phallus with an endodermally derived closed urethral tube. $C$ reconstructs the evolution of amniote external genitalia from a common ancestor with paired hemipenes and ectodermally derived open sulci spermatici. D reconstructs the independent acquisition of each of these 3 developmental events that would have occurred if the midline phallus of non-squamate amniotes is a convergent trait, and if the common ancestor of all amniotes lacked external genitalia. 
and may provide new models for human disease. Our review of external genitalia development in reptiles and birds summarizes recent advances in this area and supports the hypothesis that, despite their gross anatomical differences, external genitalia are a shared, derived character of Amniota (fig. 4).

Much remains to be learned about the molecular and morphogenetic mechanisms of external genital development in mammals and in non-mammalian species. Advances in our understanding of mouse external genital development, together with the diversity of external genital morphologies that exists across amniotes, provide a springboard for comparative studies aimed at understanding the evolution of developmental mechanisms. Moreover, understanding the evolutionary history of morphogenetic processes that are affected by congenital malformation, such as hypospadias, can provide new insights into the basis of these structural defects. External genitalia represent some of the most rapidly evolving anatomical characters in nature [Arnqvist, 1998] and, as a result, this organ system is rich with variation and evolutionary innovation. Comparative investigation into differential formation of blood versus lymphatic vasculature, for example, will help us to understand the developmental bases of the diversity in amniote erectile systems. The opossum, a marsupial mammal, has a bifid glans penis, and gene expression analysis has demonstrated that development of the distal bifid urethra in marsupials involves division of expression domains that mark the single urethra in eutherian mammals [Seifert et al., 2009b]. Does development of a bilobed mammalian urethra involve processes similar to those that generate the bifurcate sulcus spermaticus in squamate hemipenes or, alternatively, is bifurcation produced by branching events similar to those found in the lung and kidney [reviewed in Andrew and Ewald, 2010]? Such advances are beginning to be made within invertebrates [Khila et al., 2012], and continued investigation of phallus morphogenesis in a phylogenetic context has the potential to uncover new mechanisms by which developmental processes have been modified to generate the morphological diversity present in amniote external genitalia.

Further study of external genital development in nonmammalian organisms also has the potential to shed new light on the molecular mechanisms of sexual differentiation. Amniotes have an array of genetic and temperaturedependent mechanisms that control sex determination [Williams et al., 2008], but how each of these yields similar anatomical differentiation is not well understood. Furthermore, most developmental research has focused on male traits, creating a biased understanding of sexual de- velopment of the external genitalia. As discussed above, many aspects of patterning and morphogenesis are similar between males and females of particular species, yet the specific molecular triggers and downstream effectors that mediate anatomical divergence remain largely unknown for most amniotes. Hormonal triggers of sexual differentiation have been the subjects of much research during late stages of development and maturation, but how these systemic and environmental cues act on early developmental processes, often in tissue-specific manners, is not well understood. Thus, it remains unknown how and where hormonal signals interact with locally acting signaling networks to produce distinctive, sex-specific external genitalia. Increasing the depth as well as the phylogenetic breadth of understanding of these pathways and mechanisms from early morphogenesis to adult morphology and from systemic to cell type-specific regulation - has the potential to offer new insights into the development of sex-specific characters. We anticipate that discoveries in this area will be applicable to biomedical [Barlow et al., 1999; Soto and Sonnenschein, 2010], evolutionary, and conservation-related problems [Colborn et al., 1993; Frische et al., 2013].

\section{Acknowledgements}

We thank members of our laboratory and Ashley Seifert (University of Kentucky) for critical comments and stimulating discussions of the ideas presented here. M.L.G. is supported by a UF Alumni Fellowship; C.E.L. is supported by a Ruth Kirschstein National Research Service Award from the National Institute of Diabetes and Digestive and Kidney Diseases (NIH-NIDDK); F.L. is supported by a HHMI International Student Research Fellowship; A.K.L. is supported by a National Science Foundation Graduate Research Fellowship. We gratefully acknowledge support from the National Science Foundation (IOS-0843590), the National Institute of Environmental Health Sciences (R01-ES017099), and the Howard Hughes Medical Institute.

\footnotetext{
References Andrew DJ, Ewald AJ: Morphogenesis of epithelial tubes: insights into tube formation, elongation, and elaboration. Dev Biol 341:34-55 (2010).

-Arnold E: The hemipenis of lacertid lizards (Reptilia: Lacertidae): structure, variation and systematic implications. J Nat Hist 20:1221-1257 (1986a).

Arnold E: Why copulatory organs provide so many useful taxonomic characters: the origin and maintenance of hemipenial differences in lacertid lizards (Reptilia: Lacertidae). Biol J Linn Soc 29:263-281 (1986b).

Arnqvist G: Comparative evidence for the evolution of genitalia by sexual selection. Nature 393:784-786 (1998).
} 
Bakst M: Embryonic development of the chicken external cloaca and phallus. Scan Electron Microsc 1986:653-659 (1986).

Bakst MR, Cecil HC: Embryonic development of the turkey male genitalia. Poult Sci 65:16231630 (1986).

- Bandyopadhyay A, Tsuji K, Cox K, Harfe BD, Rosen V, Tabin CJ: Genetic analysis of the roles of BMP2, BMP4, and BMP7 in limb patterning and skeletogenesis. PLoS Genet 2: e216 (2006).

- Barlow S, Kavlock RJ, Moore JA, Schantz SL, Sheehan DM, et al: Teratology Society Public Affairs Committee position paper: developmental toxicity of endocrine disruptors to humans. Teratology 60:365-375 (1999).

- Beck LA, Wade J: Steroid receptor expression in the developing copulatory system of the green anole lizard (Anolis carolinensis). Gen Comp Endocrinol 157:70-74 (2008).

-Bergeron JM, Willingham E, Osborn CT 3rd, Rhen T, Crews D: Developmental synergism of steroidal estrogens in sex determination. Environ Health Perspect 107:93-97 (1999).

-Blaschko SD, Cunha GR, Baskin LS: Molecular mechanisms of external genitalia development. Differentiation 84:261-268 (2012).

Böhme W: Zur Genitalmorphologie der Sauria: Funktionelle und stammesgeschichtliche Aspekte. Bonner Zoologische Monographien 27 (Zoologisches Forschungsinstitut und Museum Alexander Koenig, Bonn 1988).

Böhme W, Ziegler T: A review of iguanian and anguimorph lizard genitalia (Squamata: Chamaeleonidae; Varanoidea, Shinisauridae, Xenosauridae, Anguidae) and their phylogenetic significance: comparisons with molecular data sets. J Zool Syst Evol Res 47:189-202 (2009).

-Brennan PL, Prum RO: The limits of sexual conflict in the narrow sense: new insights from waterfowl biology. Phil Trans R Soc Lond B Biol Sci 367:2324-2338 (2012)

- Brennan PL, Prum RO, McCracken KG, Sorenson MD, Wilson RE, Birkhead TR: Coevolution of male and female genital morphology in waterfowl. PLoS One 2:e418 (2007).

Briskie JV, Montgomerie R: Sexual selection and the intromittent organ of birds. J Avian Biol 28:73-86 (1997).

Cabrera FJ, Garcia GC: Mucins of the male genital tract of the spectacled cayman. Revista Científica (Universidad del Zulia Facultad de Ciencias Veterinarias División de Investigación) 48:77-84 (2007).

Cabrera FJ, Garcia GC, Gonzalez-Vera MA, Rossini M: Histological characteristics of the masculine genital system of the spectacled Caiman (Caiman crocodilus crocodilus). Revista Científica (Universidad del Zulia Facultad de Ciencias Veterinarias División de Investigación) 17:123-130 (2007).

Card W, Kluge AG: Hemipeneal skeleton and varanid lizard systematics. J Herpetol 29:275280 (1995).
Cohn MJ: Development of the external genitalia: conserved and divergent mechanisms of appendage patterning. Dev Dyn 240:1108-1115 (2011).

Coker CR, McKinney F, Hays H, Briggs SV, Cheng KM, Hohman W: Intromittent organ morphology and testis size in relation to mating system in waterfowl. Auk 119:403-413 (2002).

Colborn T, vom Saal F, Soto A: Developmental effects of endocrine-disrupting chemicals in wildlife and humans. Environ Health Perspect 101:378-384 (1993).

Crawford NG, Faircloth BC, McCormack JE, Brumfield RT, Winker K, Glenn TC: More than 1000 ultraconserved elements provide evidence that turtles are the sister group of archosaurs. Biol Lett 8:783-786 (2012).

-Crespo JL, Garcia-Parraga D, Gimenez I, RubioGuerri C, Melero M, et al: Two cases of pseudohermaphroditism in loggerhead sea turtles Caretta caretta. Dis Aquat Organ 105:183191 (2013).

Crews D, Cantu AR, Bergeron JM, Rhen T: The relative effectiveness of androstenedione, testosterone, and estrone, precursors to estradiol, in sex reversal in the red-eared slider (Trachemys scripta), a turtle with temperature-dependent sex determination. Gen Comp Endocrinol 100:119-127 (1995).

Dowling H, Savage J: A guide to the snake hemipenis: a survey of the basic structure and systematic characteristics. Zoologica 45:17-25 (1960).

Eberhard WG: Evolution of genitalia: theories, evidence, and new directions. Genetica 138: 5-18 (2010).

Ferguson MWJ: Reproductive biology and embryology of the crocodilians, in Gans C, Billett F, Maderson PFA (eds): Biology of the Reptilia, vol 14, pp 329-491 (John Wiley \& Sons, New York 1985).

Forbes T: Studies on the reproductive system of the alligator IV. Observations on the development of the gonad, the adrenal cortex, and the Mullerian duct. Contrib Embryol 28:132-155 (1940).

Frische T, Bachmann J, Frein D, Juffernholz T, Kehrer A, et al: Identification, assessment and management of 'endocrine disruptors' in wildlife in the EU substance legislation-discussion paper from the German Federal Environment Agency (UBA). Toxicol Lett 223: 306-309 (2013).

Gadow H: Remarks on the cloaca and on the copulatory organs of the Amniota. Philos Trans R Soc Lond B 178:5-37 (1887).

Gans C, Gillingham JC, Clark DL: Courtship, mating and male combat in tuatara, Sphenodon punctatus. J Herpetol 18:194-197 (1984).

- Garcia NM, Allgood J, Santos LJ, Lonergan D, Batanian JR, et al: Deletion mapping of critical region for hypospadias, penoscrotal transposition and imperforate anus on human chromosome 13. J Pediatr Urol 2:233-242 (2006).
Gauthier J, Kluge AG, Rowe T: Amniote phylogeny and the importance of fossils. Cladistics 4 : 105-209 (1988).

Glenister TW: The development of the penile urethra in the pig. J Anat 90:461-477 (1956).

Gredler ML, Sanger T, Cohn MJ: Development of the cloaca, hemipenes, and hemiclitores in the green anole, Anolis carolinensis. Sex Dev DOI: 10.1159/000363757 (2014a).

Gredler ML, Seifert AW, Cohn MJ: Morphogenesis and patterning of the phallus and cloaca in the American alligator, Alligator mississippiensis Sex Dev DOI: 10.1159/000364817 (2014b).

Guillette LJ Jr, Gross TS, Masson GR, Matter JM, Percival HF, Woodward AR: Developmental abnormalities of the gonad and abnormal sex hormone concentrations in juvenile alligators from contaminated and control lakes in Florida. Environ Health Perspect 102:680-688 (1994).

Guillette LJ Jr, Gross TS, Gross DA, Rooney AA, Percival HF: Gonadal steroidogenesis in vitro from juvenile alligators obtained from contaminated or control lakes. Environ Health Perspect 103 Suppl 4:31-36 (1995).

Guillette LJ Jr, Pickford DB, Crain DA, Rooney AA, Percival HF: Reduction in penis size and plasma testosterone concentrations in juvenile alligators living in a contaminated environment. Gen Comp Endocrinol 101:32-42 (1996).

Guillette LJ Jr, Woodward AR, Crain DA, Pickford DB, Rooney AA, Percival HF: Plasma steroid concentrations and male phallus size in juvenile alligators from seven Florida lakes. Gen Comp Endocrinol 116:356-372 (1999).

-Gunderson MP, Bermudez DS, Bryan TA, Degala S, Edwards TM, et al: Variation in sex steroids and phallus size in juvenile American alligators (Alligator mississippiensis) collected from 3 sites within the Kissimmee-Everglades drainage in Florida (USA). Chemosphere 56: 335-345 (2004).

-Haraguchi R, Mo R, Hui C, Motoyama J, Makino $S$, et al: Unique functions of Sonic hedgehog signaling during external genitalia development. Development 128:4241-4250 (2001).

Henry M, Burke W: The effects of in ovo administration of testosterone or an antiandrogen on growth of chick embryos and embryonic muscle characteristics. Poult Sci 78:10061013 (1999).

-Herrera AM, Shuster SG, Perriton CL, Cohn MJ: Developmental basis of phallus reduction during bird evolution. Curr Biol 23:10651074 (2013).

-Herrera AM, Brennan PL, Cohn MJ: Development of avian external genitalia: interspecific differences and sexual differentiation of the male and female phallus. Sex Dev DOI: 10.1159/000364927 (2014).

Holmes MM, Wade J: Sexual differentiation of the copulatory neuromuscular system in green anoles (Anolis carolinensis): normal ontogeny and manipulation of steroid hormones. J Comp Neurol 489:480-490 (2005). 
Hynes P, Fraher J: The development of the male genitourinary system. I. The origin of the urorectal septum and the formation of the perineum. Br J Plast Surg 57:27-36 (2004).

-Jones FW: The chelonian type of genitalia. J Anat Physiol 49:393 (1915).

Kardong KV: Vertebrates: Comparative Anatomy, Function, Evolution, ed 6 (McGraw-Hill, New York 2012).

-Katoh H, Ogino Y, Yamada G: Cloning and expression analysis of androgen receptor gene in chicken embryogenesis. FEBS Lett 580: 1607-1615 (2006).

Kelly DA: The functional morphology of penile erection: tissue designs for increasing and maintaining stiffness. Integr Comp Biol 42: 216-221 (2002).

Kelly DA: Turtle and mammal penis designs are anatomically convergent. Proc Biol Sci 271 Suppl 5:S293-295 (2004).

Kelly DA: Penile anatomy and hypotheses of erectile function in the American alligator (Alligator mississippiensis): muscular eversion and elastic retraction. Anat Rec 296:488-494 (2013).

Keppler-Noreuil KM: OEIS complex (omphalocele-exstrophy-imperforate anus-spinal defects): a review of 14 cases. Am J Med Genet 99:271-279 (2001).

Khila A, Abouheif E, Rowe L: Function, developmental genetics, and fitness consequences of a sexually antagonistic trait. Science 336:585589 (2012).

- Kim JH, Kim PCW, Hui CC: The VACTERL association: lessons from the Sonic hedgehog pathway. Clin Genet 59:306-315 (2001).

King A: Phallus, in King A, McLelland J (eds): Form and Function in Birds, pp 107-148 (Academic Press, New York 1981).

Kluge AG: Cloacal bones and sacs as evidence of gekkonoid lizard relationships. Herpetologica: 348-355 (1982).

Kluth D, Hillen M, Lambrecht W: The principles of normal and abnormal hindgut development. J Pediatr Surg 30:1143-1147 (1995).

-Kurzrock EA, Jegatheesan P, Cunha GR, Baskin LS: Urethral development in the fetal rabbit and induction of hypospadias: a model for human development. J Urol 164:1786-1792 (2000).

Larkins CE, Cohn MJ: Phallus development in the turtle Trachemys scripta. Sex Dev DOI: 10.1159/000363631 (2014).

Leal F, Cohn MJ: Development of hemipenes in the ball python snake Python regius. Sex Dev DOI: 10.1159/000363758 (2014).

Leonard JL, Cordoba-Aguilar A: The Evolution of Primary Sexual Characters in Animals (Oxford University Press, New York 2010).

- Lin C, Yin Y, Veith GM, Fisher AV, Long F, Ma L: Temporal and spatial dissection of Shh signaling in genital tubercle development. Development 136:3959-3967 (2009).

Lombardi J: Comparative Vertebrate Reproduction (Kluwer Academic, Boston 1998).
Metts JC 3rd, Kotkin L, Kasper S, Shyr Y, Adams MC, Brock JW 3rd: Genital malformations and coexistent urinary tract or spinal anomalies in patients with imperforate anus. J Urol 158:1298-1300 (1997).

-Miyagawa S, Moon A, Haraguchi R, Inoue C, Harada $M$, et al: Dosage-dependent hedgehog signals integrated with Wnt/beta-catenin signaling regulate external genitalia formation as an appendicular program. Development 136: 3969-3978 (2009).

-Moore BC, Hamlin HJ, Botteri NL, Lawler AN, Ketan K, Guillette Jr LJ: Post-hatching development of Alligator mississippiensis ovary and testis. J Morphol 271:580-595 (2011).

-Moore BC, Mathavan K, Guillette LJ: Morphology and histochemistry of juvenile male American alligator (Alligator mississippiensis) phallus. Anat Rec 295:328-337 (2012).

Mortlock DP, Innis JW: Mutation of HOXA13 in hand-foot-genital syndrome. Nat Genet 15 : 179-180 (1997).

- Paidas CN, Morreale RF, Holoski KM, Lund RE, Hutchins GM: Septation and differentiation of the embryonic human cloaca. J Pediatr Surg 34:877-884 (1999).

Paulozzi LJ, Erickson JD, Jackson RJ: Hypospadias trends in two US surveillance systems. Pediatrics 100:831-834 (1997).

Perriton CL, Powles N, Chiang C, Maconochie MK, Cohn MJ: Sonic hedgehog signaling from the urethral epithelium controls external genital development. Dev Biol 247:26-46 (2002).

Powell JS: Sexual Dimorphisms in Archosaurs: a Phylogenetic, Morphological, and Morphometric Approach. Ph.D. thesis, George Washington University, Washington (1999).

Raff R: The Shape of Life: Genes, Development, and the Evolution of Animal Form (University of Chicago Press, Chicago 1996).

Raynaud A, Pieau C: Contribution à l'étude des premiers stades de la formation des organes copulateurs chez les reptiles. Mémoires du Muséum National d'Histoire Naturelle, Nouvelle série Série A Zoologie 58, Fasc. 3 (1970).

Raynaud A, Pieau C: Embryonic development of the genital system, in Gans C, Billett F (eds): Biology of the Reptilia, vol 15, pp 149-300 (John Wiley and Sons, New York 1985).

Reese AM: The Alligator and Its Allies (Putnam's Sons, New York 1915).

Reese AM: The structure and development of the intromittent organ of the Crocodilia. J Morphol 38:301-313 (1924).

Rhen T, Sakata JT, Crews D: Effects of gonadal sex and incubation temperature on the ontogeny of gonadal steroid concentrations and secondary sex structures in leopard geckos, $E$ ublepharis macularius. Gen Comp Endocrinol 142:289-296 (2005).

Robb J: The Tuatara (Meadowfield Press Limited, Durham 1977).

Romer A, Parsons T: The Vertebrate Body, ed 6 (Saunders, Philadelphia 1986).
Rosenberg HI, Bauer AM, Russell AP: External morphology of the developing hemipenes of the dwarf chameleon, Bradypodion pumilum (Reptilia: Chamaeleonidae). Can J Zool 67: 884-890 (1989).

Ruiz CC, Wade J: Sexual dimorphisms in a copulatory neuromuscular system in the green anole lizard. J Comp Neurol 443:289-297 (2002).

-Sayag N, Robinzon B, Snapir N, Arnon E, Grimm $\mathrm{V}$ : The effects of embryonic treatments with gonadal hormones on sexually dimorphic behavior of chicks. Horm Behav 25:137-153 (1991).

Schmidt MH, Schmidt HS: The ischiocavernosus and bulbospongiosus muscles in mammalian penile rigidity. Sleep 16:171-183 (1993).

Seifert AW, Harfe BD, Cohn MJ: Cell lineage analysis demonstrates an endodermal origin of the distal urethra and perineum. Dev Biol 318:143-152 (2008).

-Seifert AW, Bouldin CM, Choi KS, Harfe BD, Cohn MJ: Multiphasic and tissue-specific roles of sonic hedgehog in cloacal septation and external genitalia development. Development 136:3949-3957 (2009a).

-Seifert AW, Yamaguchi T, Cohn MJ: Functional and phylogenetic analysis shows that Fgf8 is a marker of genital induction in mammals but is not required for external genital development. Development 136:2643-2651 (2009b).

-Seifert AW, Zheng Z, Ormerod BK, Cohn MJ: Sonic hedgehog controls growth of external genitalia by regulating cell cycle kinetics. Nat Commun 1:23 (2010).

Shea GM, Reddacliff GL: Ossifications in the hemipenes of varanids. J Herpetol 20:566568 (1986).

-Simmons MN, Jones JS: Male genital morphology and function: an evolutionary perspective. J Urol 177:1625-1631 (2007).

-Smith CA, Joss JMP: Gonadal sex differentiation in Alligator mississippiensis, a species with temperature-dependent sex determination. Cell Tissue Res 273:149-162 (1993).

- Smith CA, Joss JMP: Immunohistochemical localization of laminin and cytokeratin in embryonic alligator gonads. Acta Zool 76:249256 (1995).

-Smith CA, Elf PK, Lang JW, Joss JMP: Aromatase enzyme activity during gonadal sex differentiation in alligator embryos. Differentiation 58:281-290 (1995)

Soto AM, Sonnenschein C: Environmental causes of cancer: endocrine disruptors as carcinogens. Nat Rev Endocrinol 6:363-370 (2010).

-Stoll C, Alembik Y, Dott B, Roth MP: Associated malformations in patients with anorectal anomalies. Eur J Med Genet 50:281-290 (2007).

-Suzuki K, Bachiller D, Chen YP, Kamikawa M, Ogi $\mathrm{H}$, et al: Regulation of outgrowth and apoptosis for the terminal appendage: external genitalia development by concerted actions of BMP signaling [corrected]. Development 130:6209-6220 (2003). 
Valasek P, Evans DJR, Maina F, Grim M, Patel $\mathrm{K}$ : A dual fate of the hindlimb muscle mass: cloacal/perineal musculature develops from leg muscle cells. Development 132:447-458 (2005).

Van Dijk DE: On the cloacal region of Anura in particular of larval Ascaphus. DSc thesis, University of Stellenbosch (1959).

Wagner GP: Homology and the mechanisms of development, in Hall BK (ed): Homology: The Hierarchical Basis of Comparative Biology, pp 273-299 (Academic Press, San Diego 1994).

-Wake MH: Evolutionary morphology of the caecilian urogenital system. IV. The cloaca. J Morphol 136:353-365 (1972).

Wake MH: Hyman's Comparative Vertebrate Anatomy, ed 3 (The University of Chicago Press, Chicago 1979).

Wang Z, Pascual-Anaya J, Zadissa A, Li W, Niimura Y, et al: The draft genomes of softshell turtle and green sea turtle yield insights into the development and evolution of the turtle-specific body plan. Nat Genet 45:701706 (2013)
-Western PS, Harry JL, Graves JA, Sinclair AH: Temperature-dependent sex determination in the American alligator: AMH precedes SOX9 expression. Dev Dyn 216:411-419 (1999).

Western PS, Harry JL, Marshall Graves JA, Sinclair AH: Temperature-dependent sex determination in the American alligator: expression of $S F 1, W T 1$ and $D A X 1$ during gonadogenesis. Gene 241:223-232 (2000).

Wibbels T, Crews D: Specificity of steroid hormone-induced sex determination in a turtle. J Endocrinol 133:121-129 (1992).

-Wibbels T, Bull JJ, Crews D: Synergism between temperature and estradiol: a common pathway in turtle sex determination? J Exp Zool 260:130-134 (1991).

-Williams TM, Selegue JE, Werner T, Gompel N, Kopp A, Carroll SB: The regulation and evolution of a genetic switch controlling sexually dimorphic traits in Drosophila. Cell 134:610 623 (2008).

Woods JE, Simpson RM, Moore PL: Plasma testosterone levels in the chick embryo. Gen Comp Endocrinol 27:543-547 (1975).

Wu X, Ferrara C, Shapiro E, Grishina I: Bmp7 expression and null phenotype in the urogenital system suggest a role in re-organization of the urethral epithelium. Gene Expr Patterns 9: 224-230 (2009).
Xu K, Wu X, Shapiro E, Huang H, Zhang L, et al: Bmp7 functions via a polarity mechanism to promote cloacal septation. PLoS One 7:e29372 (2012).

- Yang JH, Menshenina J, Cunha GR, Place N, Baskin LS: Morphology of mouse external genitalia: implications for a role of estrogen in sexual dimorphism of the mouse genital tubercle. J Urol 184:1604-1609 (2010).

-Yiee JH, Baskin LS: Environmental factors in genitourinary development. J Urol 184:34-41 (2010).

-Yucel S, Dravis C, Garcia N, Henkemeyer M, Baker LA: Hypospadias and anorectal malformations mediated by Eph/ephrin signaling. J Pediatr Urol 3:354-363 (2007).

Zaher H: Hemipenial morphology of the South American xenodontine snakes: with a proposal for a monophyletic Xenodontinae and a reappraisal of colubroid hemipenes. Bull Amer Mus Nat Hist 240:1-168 (1999).

Ziegler T, Olbort S: Genital structures and sex identification in crocodiles. Crocodile Specialist Group Newsletter 26:16-17 (2007).

Zug GR: The penile morphology and relationships of cryptodiran turtles. Occas Pap Mus Zool 647:1-24 (1966). 